\title{
An overview of the wind power potential in the Romanian coastal environment - moving from onshore to offshore
}

\author{
Dragos M. Niculescu ${ }^{1,2,}$, and Eugen V. C. Rusu ${ }^{1}$ \\ ${ }^{1}$ Department of Mechanical Engineering, University of Galati „Dunarea de Jos”, 111 Domneasca Street, Galati, Romania \\ 2 Department of Oceanography, National Institute for Marine Research and Development "Grigore Antipa", 300 Mamaia Blvd., 900581, \\ Constanța, Romania
}

\begin{abstract}
In the past few years in Romania the total installed capacity reached 3025MW. Because the Europe Union is pursuing to obtain an increase in renewable energy by 2020 to cover $20 \%$ of the energy consumption with renewable energy maybe in the near future in Romania the wind energy parks will start to be build off shore where the wind energy is more powerful. From this perspective, the present work is trying to provide a better picture to the wind energy resources at the Romanian shore. The measured data was provided by NOAA [1] from different points (weather stations) four along the Romanian shore and one off-shore. The measured data was compared with data from the Global Wind Atlas model [2]. According to the analysis, there are discrepancies between the measured results and those provided by the model, but the two sets of data show that in the northern part of the off-shore the power density and the wind speed is higher than in the south.
\end{abstract}

\section{Introduction}

The study area is situated in the black sea at the Romanian coast, see fig. 1 . The sea it's an enclosed basin and it could be considered to be one of the most distant extension of the ocean, being linked to the Atlantic Ocean via three straits (Gibraltar, Dardanelles and Bosporus) and two seas (the Mediterranean and Marmara).

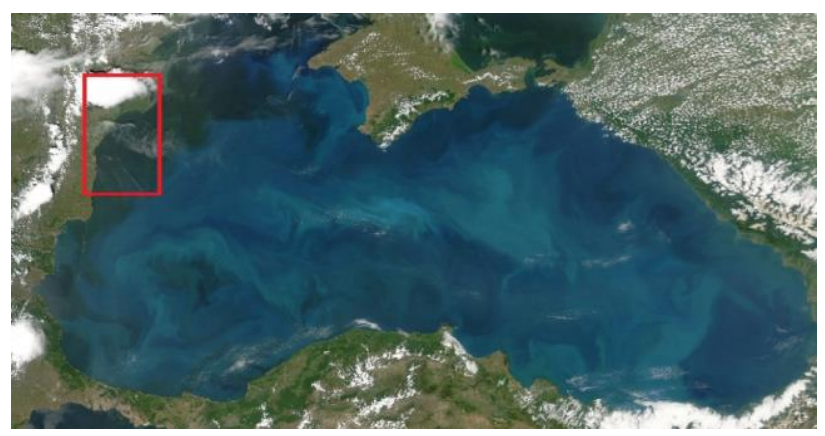

Figure 1. The Black Sea basin in the summer season - Sentinel 2 (the red rectangle encompasses the study area).

Even if it is not a very large sea, many strong storms occurs in this area (see for example Rusu, 2015 and 2016) $[3,4]$, in fact many sailors are not fond of the Black Sea because when a storm hits they have no were to go to avoid the heavy swell (one might describe it like being in a large pool). There's a real risk for marine and coastal hazards when big storms occurs (Gasparotti and Rusu, 2012) [5]. The heaviest afflicted part of the Black Sea is its westerner region were the underwater topography is the shallowest (Rusu et al., 2014) [6] and the coasts are subjected to a dynamic erosion process while others are subject to accretion processes. Furthermore, the northwestern part of the Black Sea is where the Danube River flows into the sea creating the Danube Delta and where the process of wave-current interaction are very strong with a direct influence on the neighboring coastal dynamics (Ivan et al., 2012)[7]. Many coastal works need to be carefully planned, as in some cases they might appear to be beneficial at first sight, but after a long period of time they prove to be of no help with an unwanted outcome (Omer I. et al. 2015 and Vlasceanu E. et al. 2015) [8,9].

Based on recent studies more and more attention is paid to the off-shore wind regime near the Romanian coast aiming to explain or comprehend the wind conditions as a ground for future studies regarding the hotspots for installing wind farms (Onea F. et al. 2014, $2015,2016)[10,11,12]$.

\section{Methodology}

It should be assumed that the wind speeds between the on-shore and off-shore data will differ on some degree as the roughness factor of the sea is rather small in comparison with the roughness factor on the land. Even so because the two data sets come from different outputs (e.g. measured and weather model) the data can't be compared as it is. The data sets were analyzed from different perspectives to manage a correlation and contribute in a small degree to the understanding of how the wind speed varies when scaling it in the model.

To calculate the wind power density for the measured data (from meteorological stations) the following equation (1) was used.

\footnotetext{
*Corresponding author: n.dragos8@gmail.com
} 


$$
\begin{gathered}
P_{\text {wind }}=\frac{\rho_{\text {air }} \cdot U_{x}^{3}}{2} \\
\rho_{\text {air }}-\text { represents the air density }\left(\approx 1.22 \mathrm{~kg} / \mathrm{m}^{3}\right) \\
U_{x}-\text { the wind speed reported by meteorological station }
\end{gathered}
$$

\subsection{Description of the study}

The study aims to make a correlation between the measured data and the model data. The model data are taken from the "Global Wind Atlas" while the measured data were taken from NOAA. The weather model uses the best available global datasets and the result validation is done with the help of remote sensing data from Synthetic Aperture Radar (SAR) (Alfredo Peña et al., 2015) [13]. The power density for the measured wind speed was calculated and it was put alongside with the interpolated model results.

\subsection{Onshore wind - measured}

The data used in preliminary estimations of the energetic potential were realized, corresponding to some series of data obtained from several weather stations across the shore line and one inland. The estimations are annual and there results (Table 1) show the average of annual energy potential and the standard deviation. To be noted that the M. Kogalniceanu weather station is fairly in land approximately $16 \mathrm{~km}$, in open field, as a result of this the power distribution is the smallest. The other three stations are on the coast, thus having grater power densities (Niculescu and Rusu 2016) [14].

Table 1. Preliminary estimations for the energetic potential

\begin{tabular}{cccc}
\hline Weather Station & $\begin{array}{c}\text { Yearly average } \\
\left(\mathbf{W} / \mathbf{m}^{\mathbf{2}}\right)\end{array}$ & $\begin{array}{c}\text { Standard } \\
\text { Deviation }\end{array}$ & $\begin{array}{c}\text { Wind Speed } \\
\text { Average }\end{array}$ \\
\hline Sulina & 207.9 & 57.2 & 6.21 \\
M. Kogalniceanu & 67.1 & 14.5 & 4.44 \\
Constanta & 239.6 & 62.5 & 3.58 \\
Mangalia & 83.3 & 27.7 & 3.41 \\
\hline
\end{tabular}

For Sulina, Constanta and Mangalia the height at which the data is collected is as follows $9 \mathrm{~m}, 14 \mathrm{~m}$ and respectively $9 \mathrm{~m}$. The height of $\mathrm{M}$. Koglaniceanu weather station is unknown (Cristescu T. M., 2015) [15].

Nonetheless, using the scaling formulations denoted by the Monin-Obukhov scales (2) the height of the station can be approximated to $9 \mathrm{~m}$. A graphical depiction can be seen in Figure 2.

$$
\begin{gathered}
\text { Friction velocity } u_{*}=-\overline{-u^{\prime} w^{\prime}} \\
\text { Temperature scale } T_{*}=-\frac{\overline{-w^{\prime} \theta}}{u_{*}}
\end{gathered}
$$

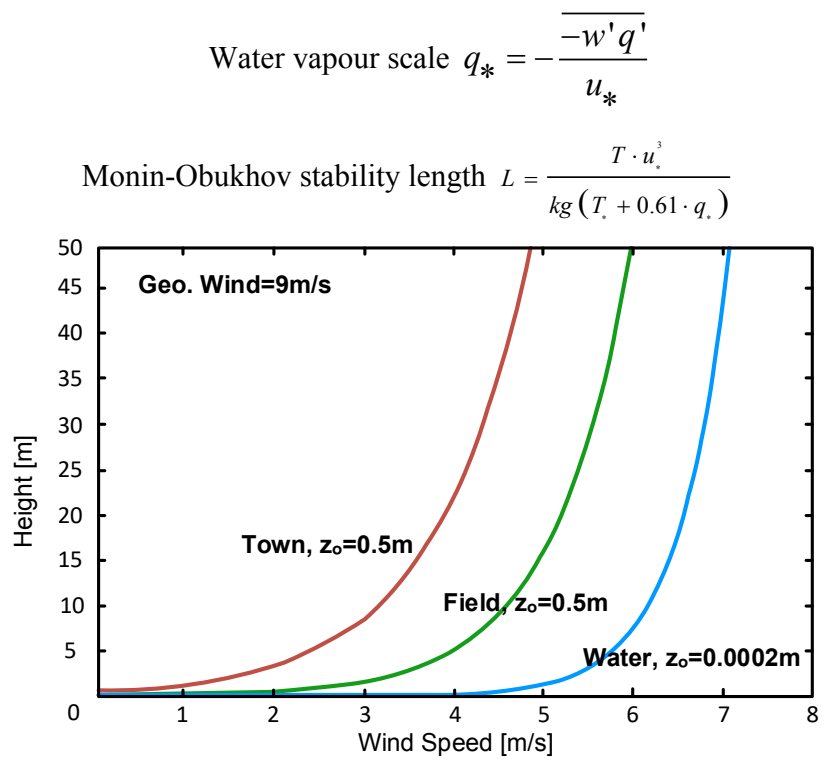

Figure 2. The change in surface wind for different roughness values, with the geostrophic wind, $G=9 \mathrm{~m} / \mathrm{s}$.

\subsection{Offshore Wind - measured}

The offshore data was collected on an oil rig between 1995 and 2007 and has almost 85000 values resulting in a wind speed average of $7.97 \mathrm{~m} / \mathrm{s}$ (Table 2) at a height of approximately 28m (Cristescu T. M., 2015) [15].

Table 2. Preliminary estimations for the energetic potential

\begin{tabular}{cccc}
\hline $\begin{array}{c}\text { Weather } \\
\text { Station }\end{array}$ & $\begin{array}{c}\text { Annual } \\
\text { average } \\
\left(\mathbf{W} / \mathbf{m}^{2}\right)\end{array}$ & $\begin{array}{c}\text { Standard } \\
\text { Deviation }\end{array}$ & $\begin{array}{c}\text { Wind Speed } \\
\text { Average }\end{array}$ \\
\hline Gloria(ANM) & 412.1 & 19 & 7.97 \\
\hline
\end{tabular}

\subsection{Offshore Wind - data resulted from the model}

It is well known that the behavior of the atmosphere is in a continuous motion, therefore it's not easy to characterize it nonetheless it can be done through the temporal periodicities and horizontal spatial scales (micro-scale, mezzo-scale and macro-scale). All this periods and scales are tied to the energy change, together contributing to the temporal variability in wind energy density in a specific location (Barthelmie R. et al., 2009) [16].

The data used in this study is a result of "The Global Wind Atlas" a free web-based application (Global Wind Atlas). The considered data points can be found in Fig. 3 (a) $50 \mathrm{~m}$, (b) $100 \mathrm{~m}$ and (c) $200 \mathrm{~m}$ altitude (standard elevation given by the model). The total number of points considered is 17 . 


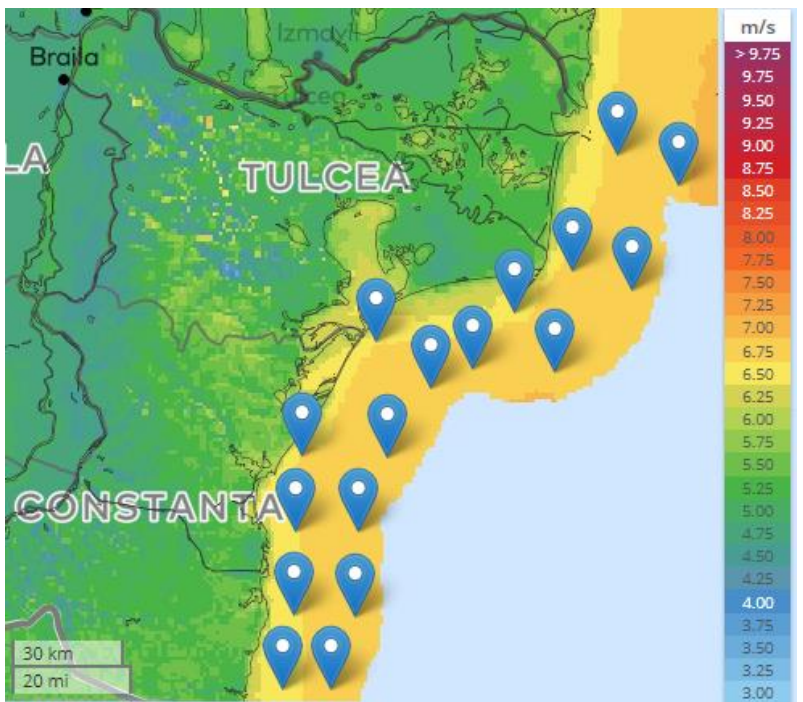

(a) $50 \mathrm{~m}$

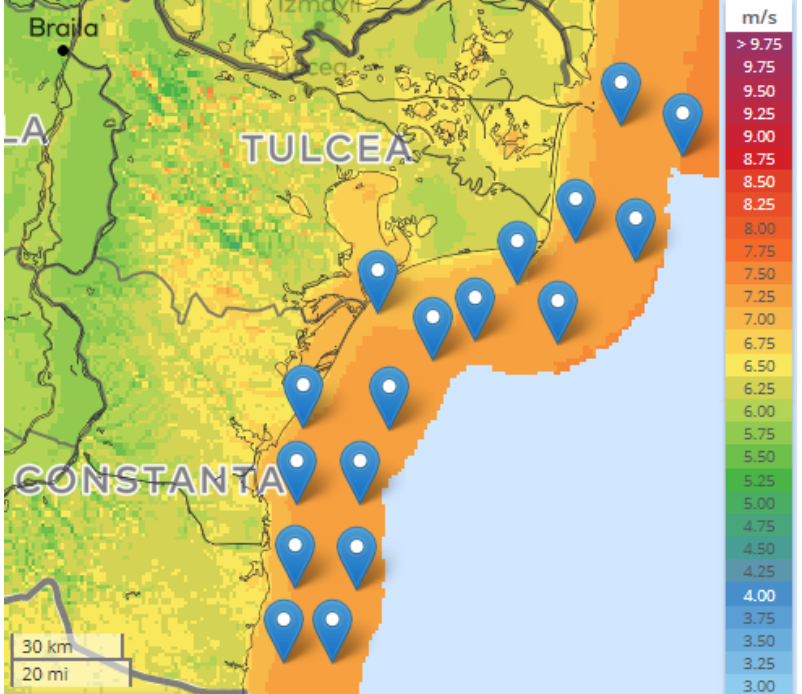

(b) $100 \mathrm{~m}$

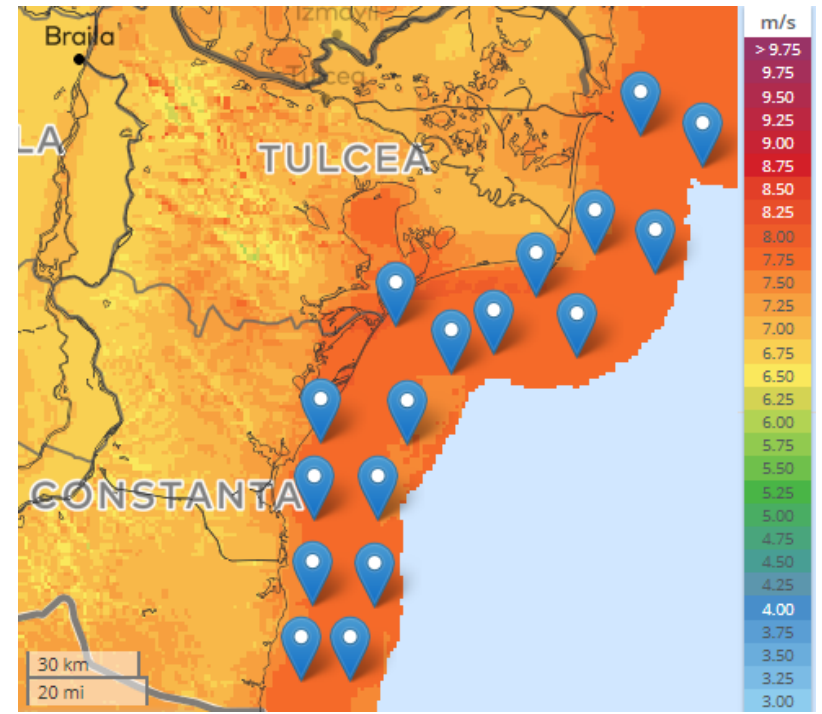

(c) $200 \mathrm{~m}$

Figure 3. Data collection points at thee elevation

\section{Results}

The measured on-shore and off-shore data sets were used alongside with the model results to obtain the interpolated result as a map using the Kriging Interpolation method.

The red diamonds represents in figure 4 the on-shore points of the weather stations, the black triangle represents the oil rig (Gloria Oil Rig) and the green dots point from where the model results were selected.

Analyzing the interpolation results between the measured data and the data results of the weather model, several particularities can be noted. First of all, the weather station data are measured at different heights than the height of the model output results. This in turn would make the measured data not relevant for the interpolation. But when noting the average wind speed that was registered at the Gloria Oil Rig at the height of $28 \mathrm{~m}$, a question can be asked: Why the wind speed is greater at this altitude than the models result at $50 \mathrm{~m}$ ? One of the answers would be that the model boundary has a limitation over the seas and oceans and because this value is at the limit it may not be correct.

The wind speed value from Sulina weather station is fairly close to the value that would correspond when estimating the values with the help of the scaling formulations, still the value is lower than the models result value of 6.61 near it. This in turn can point out that when considering an average on long wind data sets (temperature or water vapour) the state of the atmosphere is thermally neutral.

The values for Constanta and Mangalia are significantly lower; a possible explanation is that the respective meteorological stations are located in areas where there are shading effects due to post-site construction. By analysing the three maps (Figure 5) witch were a result of the interpolated model data it can be noticed how the wind velocities increase in the north part. In the third image $(200 \mathrm{~m}$ height $)$ the interpolation result shows three hot spots where the wind speed is between 7.69 and 7.75 . 


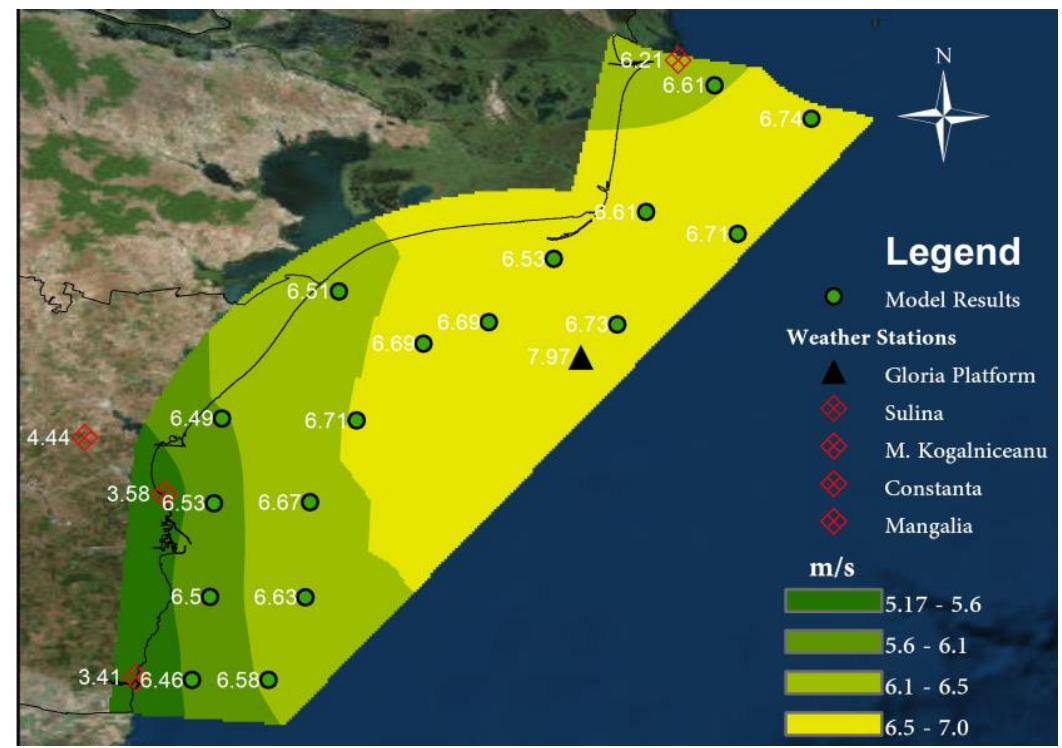

Figure 4. Wind Speed interpolation.

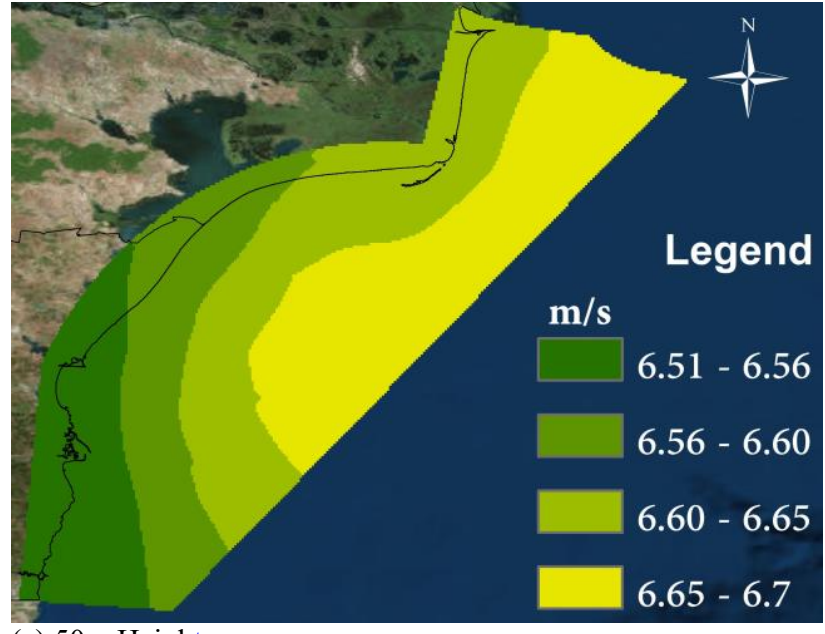

(a) $50 \mathrm{~m}$ Height

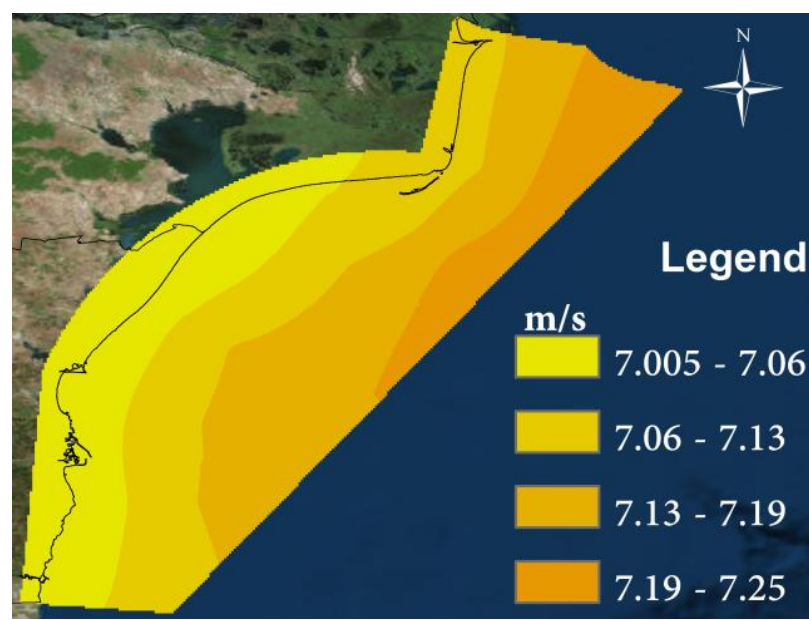

(b) $100 \mathrm{~m}$ Height

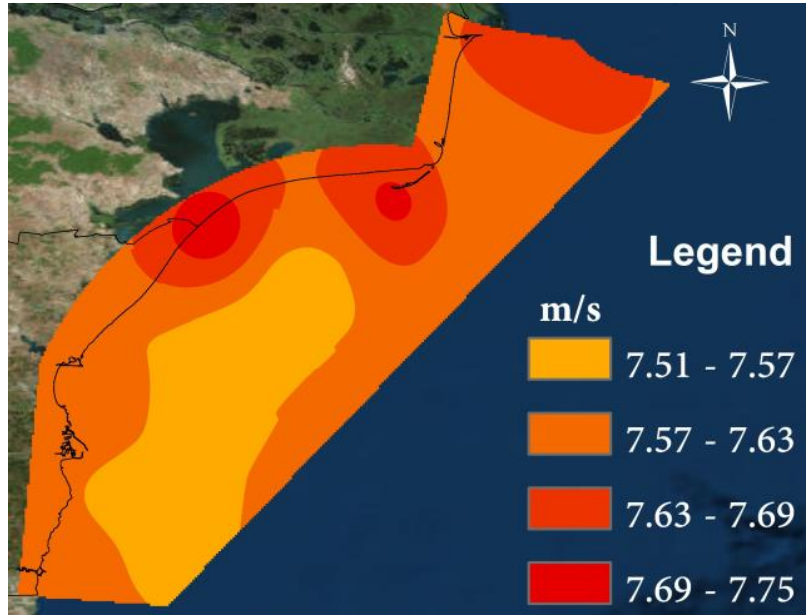

(c) $200 \mathrm{~m}$ Height

Figure 5. Wind Speed at different heights.

The interpolation of the power density data is shown in Figure 6. Based on the interpolated result, the mainland influence can be observed along the shore. In the southern part the topography is high with cliffs while in the north the orography is low do to the Danube Delta. As in the case above (Figure 4), there are differences between the measured data and model data. The value of Gloria oil rig weather station $(412.1 \mathrm{~W} / \mathrm{m} 2)$ is higher by $14.8 \%$ compared to the nearest value of the model (350.9 $\mathrm{W} / \mathrm{m} 2$ ) and it should be noted that the elevation of the weather station is lower that the model's.

A short comparison between the three images in figure 7 show how the interpolation result follows more or less the shore line. In the first image (a) $50 \mathrm{~m}$ the pattern of the interpolation mimics the shoreline. In the second image (b) $100 \mathrm{~m}$ the interpolation pattern is straighter and the maximum power density moves a bit to the north. At the height of $200 \mathrm{~m}$ the maximum power density is still in the northern part of the coast but the interpolation pattern is wavy. This phenomenon might be liked with the large scale topography (the mountain regions that surrounds the aria creating a wind corridor). 


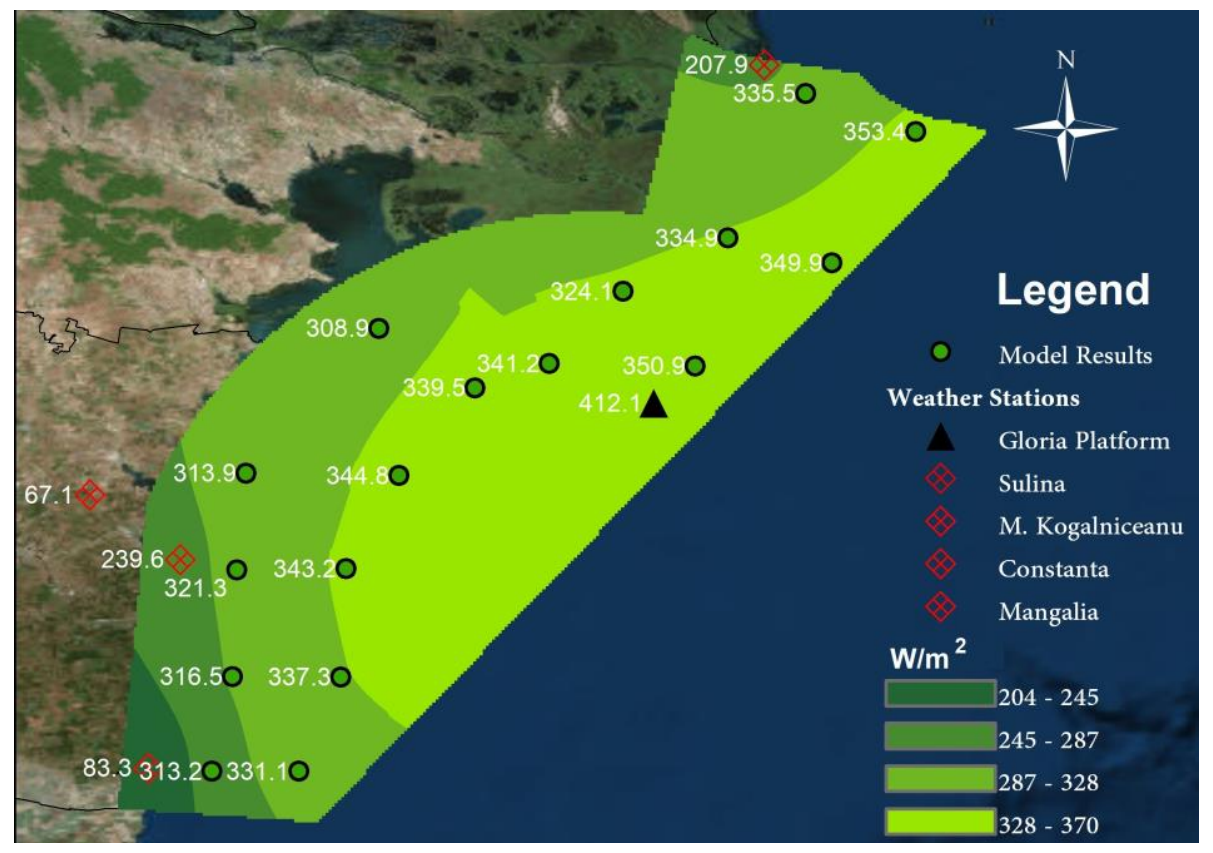

Figure 6. Power Density interpolation

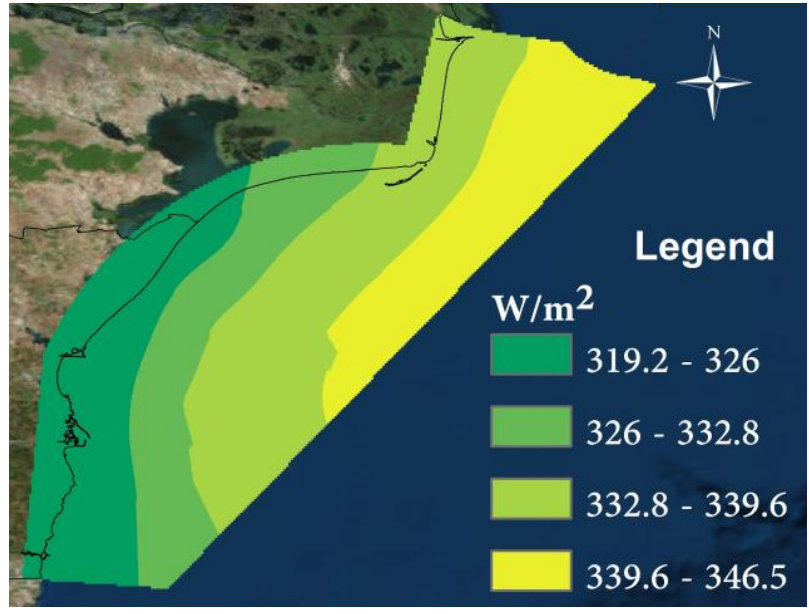

(a) $50 \mathrm{~m}$ Height

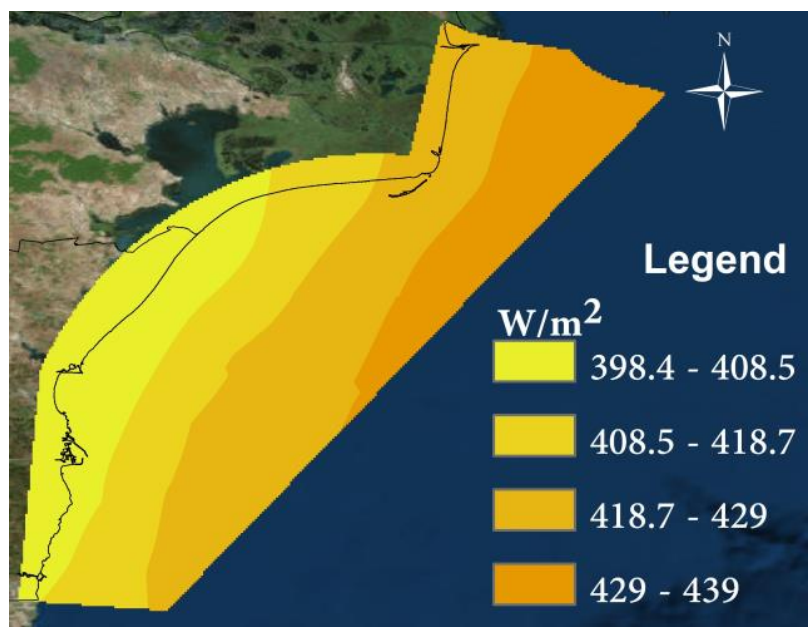

(b) $100 \mathrm{~m}$ Height

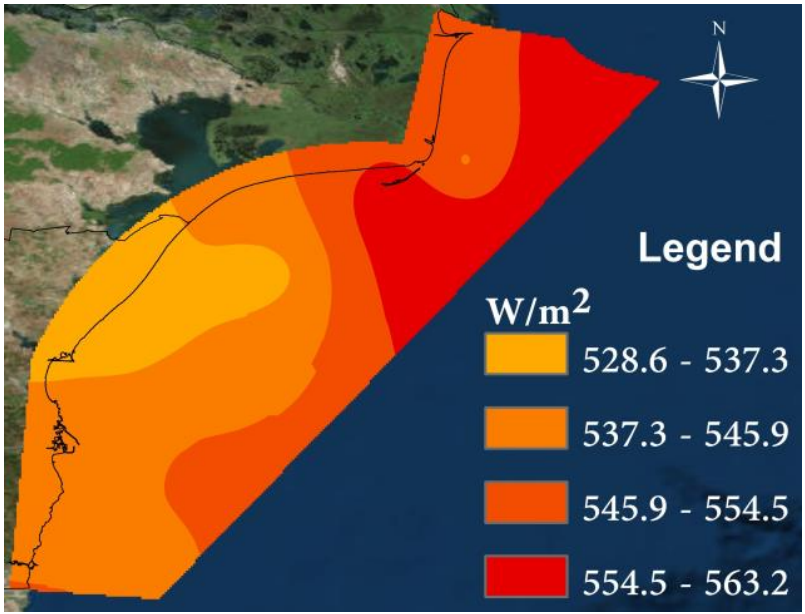

(c) $200 \mathrm{~m}$ Height

Figure 7. Power Density at different heights.

\section{Conclusions}

Based on the current study the power densities near the Romanian coastal environment are not close to the offshore power potential of some other coasts, as those from the northern seas where the wind speeds and power densities are far higher.

Nonetheless, when considering the Romanian coastal wind energy potential there might be a chance considering that the wind speed at the Gloria oil rig the mean value is $7.97 \mathrm{~m} / \mathrm{s}$ and the power density is $412 \mathrm{~W} / \mathrm{m} 2$. Furthermore, the models output data and measured data might suggest that in the northern part of the Romanian near shore, the power density is much higher than in the southern part.

The work is still ongoing and some further studies and data collection campaigns should be conducted in order 
to validate the numerical models against the measured data.

\section{Acknowledgments}

This work was carried out in the framework of the research project REMARC (Renewable Energy extraction in MARine environment and its Coastal impact), grant number PN-III-P4-IDPCE-2016-0017, financed by the Romanian Executive Agency for Higher Education, Research, Development and Innovation Funding - UEFISCDI.

\section{References}

1. NOAA National Centers for Environmental Information, https://gis.ncdc.noaa.gov/map/viewer/\#app=cd

2. Technical University of Denmark, (DTU Wind Energy), https://globalwindatlas.info/

3. Rusu, E., MATEC, 2016; 62. EDP Sciences.

4. Rusu, L., Energies, 2015; 8(9), 10370-10388.

5. Gasparotti, C. and Rusu, E. JEPE, 2012; 13(3-A), $1751-1759$
6. Rusu, L., Butunoiu, D. and Rusu, E., JEPE, 2014; 15 (2), 445-454.

7. Ivan, A., Gasparotti, C. and Rusu, E., JEPE, 2012; 13, 1673-1682.

8. Omer, I., Mateescu, R., Rusu, L., Niculescu, D. and Vlăsceanu, E., JEPE, 2015; 16(2), 417-424.

9. Vlasceanu, E., Niculescu, D., Omer I. Rusu, E. and Ivan, A., SGEM Conference Proceedings, 2015; Book3 2, 675-682.

10. F Onea, E Rusu. Meteorological Applications, 2014; 21 (2), 316-329

11. Onea, F.; Raileanu, A. and Rusu, E., Advances in Meteorology, vol. 2015; ID 808617, 14 pages.

12. Onea, F. and Rusu, E., Energy Exploration \& Exploitation, 2016; 34(2), 217-234.

13. Peña, A., Hasager, C. B., Lange, J., Anger, J., Badger, M., Bingöl, F., Würth, I. DTU Wind Energy E; No. 0029(EN)); 2013.

14. Niculescu, D. and Rusu, E., MTD, 2016; 2, 25-34.

15. Cristescu,T.M., Cercetari Marine, 2015; 45,160-172;

16. Barthelmie, R \& Pryor, Sara \& Frandsen, S.T. Offshore Wind Power, 2009; 43-70. 